\title{
Compartmentalization and evolution of feline immunodeficiency virus between the central nervous system and periphery following intracerebroventricular or systemic inoculation
}

\author{
Pinghuang Liu ${ }^{1}$, Lola C Hudson ${ }^{1}$, Mary B Tompkins ${ }^{1}$, Thomas W Vahlenkamp ${ }^{1}$, and Rick B \\ Meeker $^{2}$ \\ ${ }^{1}$ Immunology Program, College of Veterinary Medicine, North Carolina State University, Raleigh, \\ North Carolina, USA \\ ${ }^{2}$ Department of Neurology and Neurobiology Curriculum, University of North Carolina, Chapel \\ Hill, North Carolina, USA
}

\begin{abstract}
The emergence of distinct neuropathogenic strains resulting from the adaptation and the unique evolution of human immunodeficiency virus (HIV) in the brain may contribute to the development of HIV-induced neurological diseases. In this study, the authors tracked early changes in virus evolution and compartmentalization between peripheral tissues and the central nervous system (CNS) after intracerebroventricular (i.c.v.) or intraperitoneal (i.p.) inoculation of animals with cell-

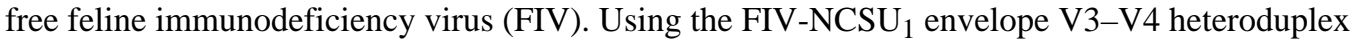
tracking assay (HTA), the authors observed a rapid compartmentalization of envelope variants between the CNS and periphery. Animals receiving the i.c.v. inoculation showed two peaks of viral RNA in the cerebrospinal fluid (CSF) with very different HTA patterns. Compared to the initial viral peak in CSF, the second peak showed an increased compartmentalization from plasma, reduced viral diversity, and more divergence from the proviral DNA in peripheral blood mononuclear cells (PBMCs) and the choroid plexus. In contrast, changes in plasma over the same time period were small. Different animals harbored different FIV DNA genotypes with varied regional compartmentalization within the brain. These results demonstrated that the virus within the CNS experienced a relatively independent but variable evolution from the periphery. Initial penetration of virus into the CSF facilitated the development of brain-specific reservoirs and viral diversification within the CNS.
\end{abstract}

\section{Keywords}

brain; cerebrospinal fluid; dementia; evolution; heteroduplex tracking assay; HIV

\section{(C) 2006 Journal of NeuroVirology}

Address correspondence to Rick B. Meeker, Department of Neurology and Neurobiology Curriculum, CB\# 7025, 6109 Neuroscience Research Building, 103 Mason Farm Road, University of North Carolina, Chapel Hill, NC 27599, USA. meekerr@neurology.unc.edu. The present address of Thomas W. Vahlenkamp is Friedrich-Loeffler-Institute, Federal Research Institute for Animal Health, Greifswald-Insel, Riems, Germany.

Publisher's Disclaimer: The publisher does not give any warranty express or implied or make any representation that the contents will be complete or accurate or up to date. The accuracy of any instructions, formulae and drug doses should be independently verified with primary sources. The publisher shall not be liable for any loss, actions, claims, proceedings, demand or costs or damages whatsoever or howsoever caused arising directly or indirectly in connection with or arising out of the use of this material. Full terms and conditions of use: http://www.informaworld.com/terms-and-conditions-of-access.pdf This article maybe used for research, teaching and private study purposes. Any substantial or systematic reproduction, re-distribution, re-selling, loan or sub-licensing, systematic supply or distribution in any form to anyone is expressly forbidden. 


\section{Introduction}

HIV-1 rapidly penetrates into the brain of most infected individuals and gives rise to a wide range of cognitive-motor symptoms ranging from undetectable to severe dementia (Davis $e t$ al, 1992; Bell et al, 1993; Gonzalez-Scarano and Martin-Garcia 2005; van Marle and Power 2005). The early penetration of virus into the central nervous system (CNS) rarely gives rise to significant neurological disease, yet is thought to set the stage for a slow, progressive deterioration of neuronal function (Gonzalez-Scarano and Martin-Garcia 2005; van Marle and Power 2005), due, in part, to the development of an inflammatory response and ultimately, the failure to control virus replication in the CNS. It has been suggested that this variability in neuropathogenesis could, in part, be due to the emergence of unique neurovirulent quasispecies in some individuals (Zink et al, 1997; Power et al, 2004; van Marle and Power 2005). Patients with human immunodeficiency virus (HIV)-1-related neurological diseases have increased viral diversity within the choroid plexus and brain (Hughes et al, 1997; van Marle and Power 2005). Viral isolates from these patients are more likely to cause neuronal apoptosis and trigger the secretion of inflammatory substances by monocytic cells compared to isolates from HIV-infected individuals without neurological diseases (Zink et al, 1997; Gorry et al, 2002; Power et al, 2004). In addition, the HIV-1 envelope (env) protein, gp120, from a neurovirulent primary HIV-1 strain required lower levels of expression of CD4 and CCR5 to enter and infect target cells than the env protein from non-neurovirulent stains with similar neurotropism (Gorry et al, 2002). All these findings suggest that distinct neuropathogenic strains may result from the adaptation of the virus to the unique environment of the brain. However, little is known about the forces that shape the evolution of the virus in the CNS. Most studies done postmortem have indicated that HIV-1 evolves in the CNS independently from HIV-1 in peripheral organs. Genetic studies comparing HIV-1 from the CNS with that in blood or peripheral organs have identified sequence differences in env, pol, gag, nef, tat, and long terminal repeats (LTRs) (Blumberg et al, 1992; Ait-Khaled et al, 1995; Wong et al, 1997; Chang et al, 1998; Smit et al, 2004; van Marle and Power, 2005). The origin of these sequence differences is not clear but could be due to either constraints on trafficking or unique interactions of the virus with cells in the CNS. One potential site for viral interactions that might support diversification is via the trafficking of virus through the choroid plexus into the cerebrospinal fluid (CSF).

The choroid plexus has been demonstrated to be a prominent site for lentiviral infection (Falangola et al, 1995; Bragg et al, 2002a; Burkala et al, 2005) and contains a mixture of viral quasispecies with sequences similar to those in both systemic organs and brain tissue (Chen et al, 2000; Burkala et al, 2005). Macrophages and dendritic cells that reside in the choroid plexus stroma (Falangola et al, 1995; Bragg et al, 2002b) are primary targets for infection but the level of productive infection of theses cells is typically low (Bragg et al, 2002a). However, these cells can efficiently transfer infection to T cells (Bragg et al, 2002a), raising the possibility that they may serve as effective vehicles for the transfer of infectious virus to other cells. Once the virus/infected macrophages penetrate into the CSF, they have access to ventricular macrophages and periventricular brain structures in an environment in which antiretroviral compounds are absent or suboptimal. These conditions may favor the development of brain-specific reservoirs and the evolution of resistant strains (Schrager and D'Souza, 1998).

In addition, the CSF pathway may serve as an effective means by which viruses exit the CNS, thereby providing a continuous flow of virus from the protected brain environment (Liu et al, 2006). In a previous study of cats infected with feline immunodeficiency virus (FIV), we found that direct inoculation of virus into the lateral ventricle gave rise to unusually high CSF viral RNA titers, a higher proviral burden in the brain, and the development of a secondary CSF peak of viral RNA at 9 to 32 weeks post inoculation (Liu 
et al, 2006). In the present study, longitudinal samples from these cats were used to evaluate FIV env V3-V4 sequence variation and compartmentalization between the CNS and periphery following intracerebroventricular (i.c.v.) or intraperitoneal (i.p.) inoculation. A high degree of compartmentalization between the CNS and periphery was observed soon after infection. Greater variation between the systemic tissues and the brain was seen after i.c.v. inoculation, indicating that early penetration of virus into the CSF facilitated the development of brain-specific reservoirs and viral diversification.

\section{Results}

\section{Plasma FIV diversity over time following systemic or i.c.v. inoculation}

All nine cats inoculated with cell-free FIV (six i.c.v., three i.p.) developed a significant infection and inversion of in the $\mathrm{CD} 4^{+}: \mathrm{CD} 8^{+} \mathrm{T}$-cell ratio. A detailed analysis of the kinetics of the plasma and CSF virus has been reported (Liu et al, 2006). The duration of the experiments ranged from 12 to 56 weeks and was based on the time required for the CSF viral loads to return to undetectable levels ( 32 to 56 weeks post inoculation, eight cats) or for the appearance of significant neurological disease (12 weeks post inoculation, cat 5). Time points were selected for heteroduplex tracking assay (HTA) analysis that represented the initial CSF viral peak (paired blood and CSF, all nine cats), the second CSF peak (paired blood and CSF, five of six cats inoculated i.c.v.), and paired blood and tissue samples collected at euthanasia. The diversification of virus was determined by comparison of samples to the original inoculum (diversification from the stock virus) as well as to the patterns seen in the first viral peak (diversification over time). A summary of FIV RNA copy numbers determined at each of the time points is provided in Table 1. Negative controls for the HTA included $\mathrm{S}^{35}$-labeled probe alone with and without the denaturing step, the mix of labeled probe with internal primers (Fenv2 and Fenv3), the polymerase chain reaction (PCR) product from the probe plasmid and samples from FIV-negative cats. The results from these controls, illustrated in Figure 1A, showed the homoduplex and/or single stranded probe but no heteroduplexes. The HTA profile for the virus inoculum was also run for comparison (Figure 1B) with samples obtained from the FIV-infected cats. All samples were run in duplicate for confirmation of the variant patterns. Examples of changes in the plasma FIV HTA patterns over time are contrasted with the inoculum profile in Figure 1B. Because all heteroduplex variants were clustered in the lower (bottom) portion of the gel, only the lower portion is shown. Based on their relative mobility, across all samples, seven distinct bands were identified and designated variant (V) V1 to V7 with V1 representing the band with the highest mobility, the homoduplex. Four diffuse bands were identified in the inoculum which corresponded to V1, V2, V4, and V6 with a relative abundance of 34.0\%, $32.4 \%, 23.3 \%$, and $10.4 \%$, respectively. To assess virus diversification over time in plasma, the HTA patterns were compared at three different times corresponding to the acute peak viremia ( 2 to 4 weeks), the period in which the second CSF peak developed ( 9 to 24 weeks post inoculation) and the euthanasia time point (32 to 56 weeks post inoculation). The HTA patterns of two typical cats are shown in Figure 1B and C. Figure 1B shows the bands in the gel and Figure 1C shows the optical density (OD) scan of the lower gel with peaks matched according to relative mobility. Dashed lines indicate the position of major bands corresponding to V1 to V7. These examples illustrate two important features of virus diversification in plasma. First, there was no significant viral env divergence between the initial viremia (at 2 to 4 weeks post inoculation) and the intermediate viremia (at 9 to 24 weeks post inoculation) in most cats (7/9). A small increase in viral diversification from the initial viremia was seen at 32 to 56 weeks post inoculation due largely to the enrichment of specific variants. Second, the patterns that developed varied considerably between cats. For example, in cat 6 a large intermediate band is enriched over time, whereas in cat 4 different variants become enriched over time. 
The average variability in the plasma HTA pattern relative to the inoculum for each cat at each time point is illustrated in Figure 2. The mean difference in the plasma HTA profile at each time point relative to the inoculum was $19.0 \% \pm 3.6 \%$ at 2 to 4 weeks, $17.4 \% \pm 2.6 \%$ at 9 to 24 weeks post inoculation, and $28.4 \% \pm 4.0 \%$ at euthanasia ( 32 to 56 weeks post inoculation), reflecting a gradual increase in diversity after 24 weeks post inoculation. When compared to the initial plasma viremia peak at 2 to 4 weeks post inoculation, a significant change in virus diversity was first seen at 32 to 56 weeks post inoculation $(t=4.804, P=$. 002). Variation in the plasma HTA pattern did not correlate with the peak viral load $\left(r^{2}=\right.$. 012 ) and occurred well after both the drop in the $\mathrm{CD} 4^{+}: \mathrm{CD} 8^{+} \mathrm{T}$-cell ratio and the appearance of the second CSF viral peak (Liu et al, 2006). A comparison of the temporal variation in HTA between the i.p. and the i.c.v. cats indicated that the cats infected intraperitoneally showed significantly greater divergence in plasma at euthanasia than did the i.c.v. cats $(38.95 \% \pm 5.06 \%$ for i.p. cats versus $22.15 \% \pm 3.17 \%$ for i.c.v cats; $t=2.992$, $P=.03)$. No significant differences between the i.p. cats and the i.c.v. cats were seen in the plasma at the 2-4 and 9-24-week time points.

\section{Compartmentalization of FIV RNA in CSF versus plasma}

Paired blood plasma and CSF samples at the first CSF viral peak and the second CSF viral peak were selected to analyze virus complexity in the CSF over time as well as the compartmentalization of FIV in CSF relative to plasma. Comparisons between the i.c.v. versus i.p. inoculated cats for the initial viral peaks in CSF were also done to indicate if introduction of virus into the ventricles resulted in an unique pattern of viral genotypes. A comparison of the HTA profiles found in the initial CSF peak with the matched plasma sample revealed only a modest difference of $25.15 \% \pm 6.3 \%$ for the i.c.v. cats and $20.01 \pm$ $9.48 \%$ for the i.p. cats. Because it is difficult to know how much of a difference represents "significant" viral diversification from normal variation, we attempted to establish reasonable guidelines. We conservatively assumed that the diversity seen across cats at the initial plasma viremia reflects natural sampling variation. The average diversity at the initial infection was $19.1 \% \pm 3.6 \%$ with an upper $95 \%$ confidence interval of $26.1 \%$. Values under this were considered to reflect random variation. Thus, based on this analysis, the slight variation in the first CSF peak relative to plasma was considered to be within the normal range.

Variation in the CSF over time was evaluated by contrasting the HTA patterns of the first peak with the second peak. Examples of the temporal changes in the HTA patterns for CSF and matched plasma samples are illustrated in Figures 3 and 4. In most cats (seven of nine), changes in the CSF HTA profile was due to enrichment of particular bands also present in plasma (Figure 3). However, the pattern that appeared in the CSF was highly variable between individual cats with no single band preferentially expressed. In two cats, a relatively unique band appeared in the CSF that was not present in the matched plasma samples. The plasma and CSF profiles for one of these cats illustrated in Figure 4 (cat 5), shows a band (V7) in the CSF at 2 and 9 weeks post inoculation that was absent in plasma. However, because of a possible presence of a very weak signal for V7 at 2 weeks post inoculation, we cannot discount the possibility that it might have been present as a minor early variant in the plasma. In this cat, V5 was also enriched in the second CSF peak relative to the first CSF peak. This was the only cat (cat 5, Figure 4) that developed significant neurological disease over the course of these experiments.

The appearance of a second peak of FIV RNA in the CSF of five of the six i.c.v. cats allowed the calculation of mean CSF FIV env variation over time. When compared to the matched plasma sample, the first CSF peak showed an average diversity of $23.4 \% \pm 5.0 \%$. The second CSF peak showed a substantial increase in diversity from the matched plasma samples $(47.4 \% \pm 12.0 \% ; P=.05)$. Because the plasma HTA profile did not change within 
this time frame (9 to 32 weeks, e.g., Figure 2), it is unlikely that it would have contributed to the increased diversity in the CSF. Examples of the types of changes seen in CSF are illustrated by the optical density (OD) profiles in Figure 5. The HTA profile for the first and second CSF viral peaks is shown in the upper portion of each figure. Dashed lines show the position of major peaks in the CSF. The FIV env divergence in the CSF over time was due to the enrichment of specific variants (Figure 5, cats 2, 3, and 4) as well as the appearance of variants unique to the CSF (Figure 5, cat 5). The expression patterns tended to simplify over time with a decrease in the average number of variants in the CSF from $3.60 \pm 0.24$ to $2.60 \pm$ 0.51. However, as seen in Figure 5, the specific bands that were enriched in the CSF varied substantially between cats indicating that there was no consistent selection for particular variants in the CSF compartment.

\section{HTA analysis of FIV DNA in brain}

Although no productive FIV infection was seen by real time reverse transcriptase (RT)-PCR in brain at euthanasia, a significant FIV DNA burden was seen in the i.c.v. cats. Comparison of the brain FIV DNA HTA patterns to CSF, plasma, peripheral blood mononuclear cells (PBMCs), and lymph nodes revealed a unique compartmentalization within the brain. The bottom panel for each of the four cats illustrated in Figure 5 shows the HTA OD profiles for the FIV env V3-V4 fragment amplified from genomic DNA extracted from four brain regions (frontal cortex gray matter, underlying cortical white matter, caudate nucleus, internal capsule/putamen) versus the CSF FIV RNA profiles (Figure 5, upper panel). Again, dashed lines show the position of major variants in the CSF. In the majority of cases, a band seen for FIV DNA in the brain had a corresponding peak for FIV RNA in the CSF. However, with the exception of cat 4, one major band appeared in each brain which was not prominent in the CSF. No two brain regions gave identical patterns nor did the patterns preferentially match to the first or the second CSF viral peak. This is well illustrated in the patterns for cat 3 (Figure 5) where the cortex (CTX), the caudate, and the internal capsule/ putamen (IC-Put) all showed different patterns. Major peaks for the cortex and internal capsule/ putamen corresponded to peaks seen in the first CSF viral peak, whereas the caudate matched closely to the second CSF viral peak.

Because periventricular structures were more likely to have been infected via the CSF, we compared HTA patterns between the brain regions in proximity to the ventricles. A significant but modest correlation $\left(r^{2}=.2052, P=.0392\right)$ was seen in the relative abundance of common variants between the choroid plexus and the first CSF peak (Figure 6A, CSF-1) but not the second CSF peak (CSF-2). A stronger correlation was seen between the periventricular caudate tissue and the subcortical white matter $\left(r^{2}=.9627, P<.0001\right)$ and choroid plexus $\left(r^{2}=.4018, P=.0149\right.$; Figure 6B). Thus, although the overall patterns of brain FIV variants indicate substantial regional diversity, the correlation between HTA patterns of periventricular structures suggested that they may share a common origin. The choroid plexus is a strong candidate for the "common" source of FIV variants and is supported by the modest correlations between choroid plexus and both the first CSF peak and the caudate. However, considerable diversity was seen between the second CSF peak and the choroid plexus $(40.2 \% \pm 10.5 \% ; t=3.82, P<.05)$ and the brain $(55.84 \% \pm 6.06 \% ; t$ $=5.50, P<.001)$, reinforcing the idea that the brain and CSF show independent variation.

\section{The contribution of infected PBMCs to brain, CSF, and plasma FIV compartments}

In a previous study of the viral kinetics within the same cats, we observed a strong correlation between the proviral burden in PBMCs and the proviral burden in the brain (Liu et al, 2006). This suggested that sequences isolated from brain largely reflected the penetration of cells from the systemic circulation. If this assumption was correct, we would expect the HTA patterns in the brain to closely match the patterns seen in PBMCs. To begin 
to address the extent to which infected PBMCs might contribute to FIV in various compartments, we compared HTA patterns of DNA extracted from PBMCs to the patterns seen in temporally matched samples of the brain, CSF, plasma, and lymph nodes (Figures 7 and 8). Analysis of the HTA profiles for DNA isolated from PBMCs revealed a surprising homogeneity across all cats with an average variation of $15.7 \% \pm 2.4 \%$. However, as illustrated in Figure 7, a comparison of the HTA patterns of the PBMCs to those of matched cortex and basal ganglia revealed considerable variation of $39.4 \% \pm 7.5 \%(t=3.18, P=$. $0072)$ and $49.4 \% \pm 11.4 \%(t=3.33, P=.0060)$, respectively. The choroid plexus showed only modest variation $(20.3 \% \pm 6.1 \%$, not significant) from PBMCs. However, although relative expression patterns differed greatly, most brain variants were also detected in the matched PBMCs for the majority of the i.c.v. cats (5/6). Cat 2 was the only exception where V3, a major proviral variant in the caudate, was not seen in the PBMCs. An example of the different HTA patterns seen across various tissues sampled from cat 5 is illustrated in Figure 8. A similar HTA pattern was seen in the PBMCs, lymph node, and the choroid plexus, in which five variants were identified (V1, V2, V4, V5, and V7). The percent difference between PBMCs and lymph node was $10.0 \%$ and the percent difference between PBMCs and choroid plexus was $10.60 \%$, indicating relative homogeneity. In contrast, each brain region showed a distinct pattern with different variants concentrated in each region.

When PBMC HTA was compared to matched plasma samples across all cats, an average percent difference of $24.2 \% \pm 3.8 \%$ was calculated for the initial viremia at 2 to 4 weeks post inoculation and remained at a similar level of $25.9 \% \pm 4.6 \%$ until euthanasia. The diversity between PBMCs and plasma at euthanasia was greater for the i.p. cats $(38.22 \% \pm$ $4.24 \%)$ than for the i.c.v. cats $(19.70 \% \pm 4.98 \%)$. A similar difference in diversity between the i.c.v. cats and the i.p. cats was seen when PBMCs were compared to the superficial cervical lymph nodes where the i.p. cats showed a difference of $27.07 \pm 5.13 \%$ versus $11.44 \% \pm 2.14 \%$ in the i.c.v. cats. Comparison of PBMCs HTA profiles to changes in CSF over time showed that PBMCs were relatively stable over time and the pattern of FIV DNA in PBMCs paralleled the profiles seen for FIV RNA isolated from the first CSF peak $(26.21 \% \pm 5.58 \%$ difference) much more closely than for the second peak $(45.87 \% \pm 6.85 \%$ difference; $t=5.51, P=.0053$ ). Thus, the relative homologies between the HTA sequences for PBMCs and the HTA for plasma, lymph nodes, and the first CSF peak are consistent with PBMCs being a significant source of virus in these compartments whereas the substantial differences between PBMCs and the brain and second CSF peak suggest an independent source of virus.

\section{Neurological consequences of i.c.v. inoculation and HTA patterns}

Only one cat (cat 5) showed overt neurological symptoms resulting from the i.c.v. infusion of FIV. Symptoms developed approximately 12 weeks after inoculation and included profound depression with an absence of postural responses in all limbs. Patellar reflexes were mildly exaggerated and withdrawal reflexes in all limbs were normal. On cranial nerve testing, the pupillary light reflex was slow bilaterally and there was a positional nystagmus present. This nystagmus was oriented vertically with the fast phase in a ventral direction. The cat had normal facial symmetry with normal palpebral reflexes. Jaw tone and tongue movements appeared to be normal. The appearance of the neurological symptoms coincided with a large second peak of increased viral load in the CSF $\left(5.1 \times 10^{5}\right.$ copies $/ \mathrm{ml}$, three-fold higher than the initial peak in CSF), an inversion of the CSF:plasma ratio, and an HTA profile with a relatively unique CSF variant (V7, Figure 4). This cat also showed the highest average brain proviral burden with 270 copies/ $\mu \mathrm{g}$ DNA versus 46 copies/ $\mu \mathrm{g}$ DNA for all other i.c.v. cats. All other cats, including those infected intraperitoneally, were asymptomatic for neurological or systemic disease. The inital analysis of brain tissue in cat 5 has shown very little gross pathology, no clear damage in cresyl violet stained sections and a 
few small clusters of Mac387-positive macrophages. It is currently unclear if the neurological symptoms correlate with observable pathological changes. More detailed neuropathological studies are underway to define subtle changes that might be associated with this and other cats receiving i.c.v. inoculation of FIV.

\section{Discussion}

High rates of mutation and replication of HIV and other lentiviruses allow for the continuous generation of genetically heterogeneous quasispecies in vivo (Delwart et al, 1993; Power et al, 2004; van Marle and Power 2005). This facilitates the development of variants with different cell tropism, allows escape from immune inactivation, increases the level of virulence, and leads to antiretroviral drug resistance (Gorry et al, 2002; Power et al, 2004; van Marle and Power 2005). Selective pressures that allow the emergence of different viral quasispecies and strains vary between tissue compartments but are still poorly understood. This is particularly true in the unique environment of the brain that may harbor a persistent viral reservoir partially protected from typical immune surveillance and antiretroviral drugs (van Marle and Power 2005). A growing body of evidence from studies of CNS infection, HIV evolution, and CSF virology indicate that the trafficking of virus through the choroid plexus into the CSF may contribute significantly to viral evolution and CNS infection (Petito et al, 1999; Chen et al, 2000; Bragg et al, 2002a; Burkala et al, 2005).

In the present study, the FIV model was used to track viral env evolution during the early stages of infection. FIV shares many common characteristics with HIV-1 in molecular structure and pathogenesis (English et al, 1994; Boche et al, 1996; Willett et al, 1997; Power et al, 2004). FIV infects primarily T lymphocytes, macrophages, and CNS glial cells, similar to the cell tropism exhibited by HIV-1 and simian immunodeficiency virus (SIV) (Dow et al, 1992; English et al, 1993). Like HIV, FIV is a natural infection of domestic cats resulting in immune deficiency in all infected cats and CNS diseases in a subset of infected cats (English et al, 1994; Phillips et al, 1994; Power et al, 1998). This animal model affords the opportunity to study the evolution of FIV in parallel with changes in immune function and pathogenesis.

Our studies of systemic and CSF viral kinetics following direct inoculation of FIV into the CSF showed an increased incorporation of FIV DNA in the brain and a unique pattern of FIV expression in the CSF (Liu et al, 2006). Samples from these cats were used in the present study to examine the evolution of $e n v$ variants during the early stages of infection. We found that inoculation of FIV into the CSF gave rise to a distinct compartmentalization of variants between the CNS and the periphery. In addition, significant variation was seen over time in both plasma and CSF, including the appearance of three variants (V3, V5, V7) identified in the viral RNA and tissue proviral DNA that were not present in the inoculum.

The above observations indicated that FIV env sequences changed rapidly after infection. These changes are consistent with other observations indicating that the V3-V5 region contributes to FIV neurotropism and neurovirulence (Johnston and Power, 2002). We focused on env $\mathrm{V} 3-\mathrm{V} 4$ because this region has a high degree of variability, possesses determinants involved in macrophage tropism, and affects the release of neurotoxic molecules (including the envelope protein gp120 itself) following infection of macrophages (Power et al, 1994, 2004; Nelson et al, 1997). These properties have made this region a target of many studies of HIV-1 evolution (Epstein et al, 1991; Scarlatti et al, 1997; Chen et $a l$, 2000; Strain et al, 2005). However, it is important to note that $e n v$ variation may be only one of many determinants of viral compartmentalization in the CNS. Indeed, studies have indicated that long terminal repeat (LTR), gag, and nef sequences also show variation that is relatively unique to the CNS and this sequence variation may contribute to neurotropism, 
neurovirulence, and resistance to antiretroviral drugs (Corboy and Garl, 1997; TorresMunoz et al, 2001; Hogan et al, 2003; Burdo et al, 2004; Smit et al, 2004; van Marle et al, 2004). It is possible that in the relative absence of neutralizing antibody, these factors might play a greater role than env in CNS infection and virus diversification. Morris et al (1999) has suggested that a mosaic of variants may ultimately be a better predictor of neurotropism than any single variant. Thus, whereas sequence variation can be a good index of tissue specific variation, it must be interpreted cautiously and ultimately validated in vitro and in vivo.

\section{FIV env variation in the CSF}

Similarities between the initial HTA profiles in plasma, PBMCs, choroid plexus, lymph nodes, and CSF suggested a common source of infection. Viral variants within the choroid plexus matched sequences from PBMCs and plasma better than brain, suggesting that its virus load predominantly reflects infiltrating cells. This is consistent with the commonly observed infection of the choroid plexus. Studies of HIV env V3 sequence variation in postmortem tissue have shown that the choroid plexus contained an admixture of sequences typical of sequences in both brain and spleen (Chen et al, 2000; Burkala et al, 2005). This raises the possibility that the unique environment of the choroid plexus could facilitate the development of neurotropic quasispecies. The most likely source for the early appearance of viral RNA in the CSF is trafficking immune cells. Macrophage and cellular barriers between the vasculature and the choroid plexus epithelium would most likely restrict passage of cellfree virus from the blood into the CSF. T cells and monocytes trafficking into the choroid plexus stroma would find themselves in an environment heavily populated by resident macrophages. Cellular and infectious interactions within the stroma may facilitate adaptation of the virus to the CNS environment (Falangola et al, 1995) through the expression of mixed virus populations (Chen et al, 2000). Strong similarities between the HTA patterns in the CSF FIV RNA and the choroid plexus FIV DNA support this general view for the initial stages of infection. However, the HTA profiles of the second CSF peak contrasted dramatically with the first CSF viral peak and the choroid plexus, suggesting that this delayed virus production had an independent origin. The large variation seen in the CSF at the second viral peak was particularly noteworthy because it developed before any detectable variation in plasma FIV. The uniqueness of the second CSF HTA profile was also reinforced by the lack of correlation with plasma FIV RNA as well as DNA from PBMCs and systemic tissues. Thus, the intraventricular inoculation with FIV appears to set the stage for a rapid diversification of FIV env within the CNS. Specific variants enriched in the CSF differed from cat to cat, indicating that the selective pressure within the brain was not highly focused to a particular sequence. It should be noted, however, that the variation seen in the second CSF viral peak was largely due to reduced viral HTA complexity rather than the appearance of new variants. The enrichment of CSF variants that are also detected in plasma is similar to studies of HIV-1 in human CSF where selective enrichment was found to be more common than the generation of new quasispecies (Ritola et al, 2005; Harrington et al, 2005).

The most consistent interpretation of the viral diversity seen in the second CSF peak is the transient local synthesis of new virus occurring soon after the drop in the $\mathrm{CD} 4^{+}: \mathrm{CD} 8^{+} \mathrm{T}$-cell ratio. The trigger for this delayed virus production is not known. This interpretation is supported by studies of Ryan et al (2003), which showed that initial infection of cats with FIV was followed by a transient productive infection of the brain with a time course similar to the appearance of our second CSF peak. In their studies, virus was cleared from the CNS by 30 weeks. This is approximately the same time that we observed the loss of detectable virus in the CSF. Together, these observations suggest that viral evolution in the brain is relatively rapid and independent of circulating virus. 


\section{FIV env variation in brain}

The widespread incorporation of FIV DNA into brain in the i.c.v. cats allowed a comparison of regional differences. Considerable variation in the FIV DNA HTA patterns was seen between brain regions in the same cats as well as between cats. As with the CSF, different brain regions often displayed a selective enrichment of one or two variants. However, no consistent relationship was seen between the CSF FIV variants and the regional FIV DNA sequences in brain. In some cases a strong relationship was found between the HTA pattern of CSF RNA and the HTA pattern in a particular brain region. This was most often the case for the caudate nucleus but, again, the particular variant that was enriched varied between cats. The variable env genotypes of the FIV proviral quasipecies in separate brain regions within the same cat was consistent with previous findings for HIV-1 in which subpopulations independently evolved in different brain regions (Chang et al, 1998; Shapshak et al, 1999). A caveat of these studies that must be kept in mind lies in the fact that no productive infection was seen in the brain at the time of euthanasia. Because the intention of the study was to follow the fate of the CSF virus until viral loads became negligible, it is likely that a transient local virus production in the parenchyma was missed. Consequently, we can only infer what quasispecies might come from the brain based on the available sequences in the DNA. The lack of a clear relationship between brain and CSF HTA patterns on the one hand suggests that the brain contributes little to CSF virus. The appearance of variants in the CSF that were not seen in FIV DNA sequences in brain tissue support the contribution virus from non-CNS sources. However, no systemic source could easily account for the diversification seen in the CSF over time. It is possible that the CSF profiles reflect the selective synthesis of certain variants from the brain. In this case the brain DNA HTA pattern would not reflect actual viral RNA coming from the brain compartment. Variants prominent in the caudate were often found to be prominent in the second CSF sample, providing some indirect support for this view. Overall, the mixed pattern of variants is consistent with the view that the CSF contains sequences of both systemic and brain origin.

The weak relationship between proviral HTAs of PBMCs and brain indicated that trafficking cells did not contribute directly to the brain profile. However, in most cases, variants in the brain were also present in PBMCs, with differences due to the relative abundance of individual variants. Thus, PBMCs appear to make little direct contribution to the diversity seen in brain, although we cannot rule out the possibility that selective trafficking of different cell subsets (with unique HTA profiles) might contribute to the differential patterns. Although no clear relationship was seen between the variant patterns in brain versus other compartments, several observations suggested that virus trafficking through the CSF may have contributed to viral evolution in specific brain regions. When we compared HTA patterns in periventricular structures that should be particularly vulnerable to infection via the CSF inoculation (caudate at the lateral border of the ventricle, cortical white matter along the dorsal border of the ventricle, and the choroid plexus within the ventricle), we found similar patterns of expressed variants. Variant patterns from other brain tissue samples more remote from the ventricles (internal capsule/putamen and cortical gray matter) did not correlate. A significant, albeit lower, correlation was also seen between the variants expressed in the caudate versus those seen in the choroid plexus. Thus, a specific correlation between periventricular regions suggested a common origin and evolution of the FIV.

Only one variant (V7) emerged that appeared to be somewhat unique to the CNS. Other studies have demonstrated unique quasispecies of HIV in the CSF relative to plasma (Ritola et al, 2005). Variant V7 was seen in two cats, one of which developed neurological symptoms. Although it is tempting to speculate that this virus may represent a more neurovirulent species, its role in pathogenesis remains to be determined. The absence of this 
variant in the brain tissue DNA, choroid plexus, or PBMCs makes the origin uncertain. In addition, the absence of overt pathology in the brains of these cats indicates that the significance of this variant needs to be interpreted cautiously until more detailed pathological studies are done and further data are collected to support the neurovirulence.

In summary, infection of the brain and viral diversification was greatly enhanced in the cats receiving the i.c.v. inoculation, providing support for the hypothesis that initial virus trafficking thorough the CSF plays an early and important role in infection and diversification. A distinct compartmentalization of variants was seen within the CSF and brain, although the patterns were highly variable across brain regions and between cats. The extent of FIV env diversity in CSF and brain relative to other tissues indicates that the CNS is an important site for viral diversification but the underlying mechanisms are still poorly understood. A better understanding of this process is needed to develop effective therapeutic interventions that control early deleterious HIV interactions with the CNS.

\section{Materials and methods}

\section{Animals, virus challenge, and collection of samples}

The specific pathogen-free (SPF) cats used in the study were screened for FIV and other common feline infections as previously described (Liu et al, 2006). Briefly, six adult cats at 10 to 18 months of age were intracerebroventricularly inoculated with a total of $200 \mu \mathrm{l}$ ( $2 \times$ $10^{5} \mathrm{TCID}_{50}$ ) cell-free $\mathrm{NCSU}_{1}$ FIV into the right lateral ventricle using a sterotaxic apparatus (Liu et al, 2006). To provide a comparison to systemic infection, three additional cats were inoculated intraperitoneally with an identical amount of cell-free FIV $\left(2 \times 10^{5} \mathrm{TCID}_{50} / 200\right.$ $\mu 1)$. Blood and CSF samples were collected prior to infection and at 1, 2, 4, 6, 9, 12, 16, 20, 24 , and 32 weeks post inoculation. Some cats included samples at 40, 48, and 56 weeks post inoculation as well. The development of significant neurological disease or the complete clearance of viral RNA from the CSF was used as the endpoints for the studies. Only one cat (cat 5) manifested neurological symptoms at 12 weeks after infusion of cell-free virus. All animal procedures were performed in accordance with National Institutes of Health guidelines and were reviewed and approved by the North Carolina State University College of Veterinary Medicine Institutional Animal Care and Use Committee.

\section{Preparation of virus inoculums}

The $\mathrm{NCSU}_{1}$ strain of FIV, originally isolated from a naturally infected cat with lymphopenia and acute enteritis, has dual T-cell and macrophage tropism (English et al, 1993; Bragg et $a l, 2002 \mathrm{a}$ ). Cell-free virus inoculum was prepared as described previously (English $e t a l$, 1993). Briefly, pooled PBMCs from $\mathrm{NCSU}_{1}$ infected cats were cocultured with a feline interleukin (IL)-2-dependent CD4 ${ }^{+} \mathrm{T}$-cell line (FCD4E cells). Cell supernatant containing high RT activity was collected, filtered $(0.2 \mu \mathrm{m})$, and frozen as a source of virus stock. Virus titer was determined by the $50 \%$ tissue culture infectious dose $\left(\mathrm{TCID}_{50}\right)$ method as described by Davidson et al (1993).

\section{Viral RNA and DNA extraction}

Viral RNA was extracted from $400 \mu 1$ of CSF or plasma using QIAamp Viral RNA Mini Kit (Qiagen, CA) according to the manufacturer's protocol. Genomic total DNA was isolated from a $30 \mathrm{mg}$ sample from four brain regions (frontal cortex gray matter, underlying cortical white matter, caudate nucleus, and internal capsule/putamen), the choroid plexus, and superficial cervical lymph node or from $1 \times 10^{6}$ PBMCs using QIAamp DNA mini kit (Qiagen) according to the manufacturer's protocol. 


\section{Reverse transcription}

The viral RNA was reverse transcribed by using Omniscript RT Kit (Qiagen). Briefly, RT reaction mixtures consisted of $5 \mu \mathrm{l}$ of purified viral RNA, $4 \mathrm{U}$ of Omniscript Reverse transcriptase, $0.5 \mathrm{mM}$ of each dNTP, $1 \mu \mathrm{mol}$ of reverse primer (Fenv6, seen below), and 10 $\mathrm{U}$ of RNase inhibitor (Promega, WI) in a total volume of $20 \mu \mathrm{l}$. Reaction mixtures were incubated at $37^{\circ} \mathrm{C}$ for $60 \mathrm{~min}$ and followed by $95^{\circ} \mathrm{C}$ for $3 \mathrm{~min}$ to inactivate Omniscript Reverse transcriptase.

\section{PCR}

An aliquot containing 0.1 to $1 \mu \mathrm{g}$ of genomic DNA or $5 \mu \mathrm{l}$ cDNA was added to a first-round reaction of $50 \mu \mathrm{l}$ containing $1 \times$ Hotstart PCR buffer, $2.5 \mathrm{U}$ HotStart Taq DNA Polymerase, $200 \mu \mathrm{M}$ of each dNTP, $0.5 \mu \mathrm{mol}$ of each first-round primers (Fenv1-forward and Fenv6reverse) (Fenv1-5'-946GCTATTGTACAGACCCATT AC-3';

Fenv6-5'-1605GTACAGTTACAATTCATATACCC-3'). Outer terminal primers (Fenv1 and Fenv6) amplified a 699-bp fragment, covering all of the V3 and V4 regions. A volume of $2 \mu 1$ of the product of the first PCR reaction was added to $50 \mu 1$ of the second PCR mix, containing $1 \times$ Hotstart PCR buffer, $2.5 \mathrm{U}$ HotStart Taq DNA Polymerase, $200 \mu \mathrm{M}$ of each dNTP, $0.5 \mu \mathrm{mol}$ of each internal primer Fenv2 and Fenv3 (Fenv2-5'-971TCCCACTGATCAATTATACATTTGG-3'; Fenv3-5'-1407GTCATCTACCTTCATAGTAAACCCG-3'). Standard PCR parameters were $95^{\circ} \mathrm{C}$ for 15 min to activate HotStart Taq DNA Polymerase, 30 cycles of $94^{\circ} \mathrm{C}$ for $15 \mathrm{~s}$, $58^{\circ} \mathrm{C}$ for $30 \mathrm{~s}$ (or $56^{\circ} \mathrm{C}$ for $30 \mathrm{~s}$ during the second round), and $72^{\circ} \mathrm{C}$ for $1 \mathrm{~min}$. Each round was followed by a final extension at $72^{\circ} \mathrm{C}$ for $7 \mathrm{~min}$. An aliquot of $8 \mu \mathrm{l}$ nested PCR product was first analyzed by agarose gel electrophoresis for a single, ethidium bromide-staining band to check the correct molecular weight and concentrations.

\section{Probe labeling with BamHI and Ndel}

FIV NCSU 1 V3-V4 probe was a kind gift from Dr. Ronald Swanstrom (University of North Carolina at Chapel Hill). Briefly, probes were constructed by amplification from $\mathrm{NCSU}_{1}$ FIV molecular clone JSY3 using primers specific to V3-V4 (Yang et al, 1996). PCR products were cloned into the pT7Blue vector by using the Perfectly Blunt cloning kit (Novagen, CA). An aliquot of $10 \mu \mathrm{g}$ of probe DNA was digested with $\mathrm{BamHI}$ at $37^{\circ} \mathrm{C}$ for 1 $\mathrm{h}$. The probe in the BamHI reaction buffer was labeled by filling in the BamHI overhangs after adding $50 \mu \mathrm{M}$ dGTP, $50 \mu \mathrm{Ci}$ of $\left[\alpha^{-35} \mathrm{~S}\right] \mathrm{dATP}(1,250 \mathrm{Ci} / \mathrm{mmol}$; NEN Life Science Products, MA), and $10 \mathrm{U}$ of Klenow fragment of DNA polymerase I (NEN Life Science Products) in $73.5 \mu \mathrm{l}$ for $15 \mathrm{~min}$ at room temperature. The DNA polymerase was inactivated by the addition of $10 \mathrm{mM}$ EDTA. The unincorporated nucleotides were removed by using a QIAquick PCR purification kit (Qiagen) and eluting in a final volume of $50 \mu 1$. The probe was released from the plasmid by digestion with NdeI (NEN Life Science Products, MA) at $37^{\circ} \mathrm{C}$ for $1 \mathrm{~h}$, and $\mathrm{NdeI}$ was inactivated at $65^{\circ} \mathrm{C}$ for $20 \mathrm{~min}$.

\section{Heteroduplex tracking assay}

FIV envelope V3-V4 sequence heterogeneity was evaluated using the heteroduplex tracking assay (HTA), an assay based on mobility alteration of DNA heteroduplexes (Delwart $e t a l$, 1993; Nelson et al, 1997). Identical size fragment probe and target DNA were used to generate a heteroduplex. Heteroduplex annealing reaction mixtures consisted of $7 \mu 1$ of unpurified PCR product, $1 \mu$ of $10 \times$ annealing buffer $(1 \mathrm{M} \mathrm{NaCl}, 100 \mathrm{mM}$ Tris- $\mathrm{HCl}[\mathrm{pH}$ 7.5], $20 \mathrm{mM}$ EDTA), $1 \mu 1$ of labeled probe, and $1 \mu 1$ loading dye in a total volume of $10 \mu \mathrm{l}$. The mixture of PCR amplicons and labeled probe were denatured at $95^{\circ} \mathrm{C}$ for $2 \mathrm{~min}$ followed by annealing at room temperature for $5 \mathrm{~min}$. The heteroduplexes were separated by electrophoresis in a 6\% naïve polyacrylamide gel (acrylamide-bisacrylamide, 37.5:1) in 1× 
Tris-borate-EDTA buffer by using a model V16-2 vertical gel apparatus run at $17 \mathrm{~mA}$ per gel for $5.5 \mathrm{~h}$. The DNA was allowed to migrate until the fastest migrating DNA (homoduplex) nearly reached the bottom of the gel. The gels were dried and exposed to xray film. Heteroduplex bands should be located between the single probe and homoduplex band. All amplifications and HTA analyses were run in duplicate to validate the quality of sampling. To quantify the relative abundance of each band, a digital scan of the optical density was made over the same length (same number of pixels) of each lane within a gel starting at the loading site and ending just below the homoduplex band. The average optical density across the width of the lane was calculated at each position to give the optical density profile with a resolution of approximately $0.1 \mathrm{~mm}$. Bands were matched based on their relative mobility within the gel calculated as the distance from the loading site to the band as a proportion of the distance from the loading site to the homoduplex band. The signal intensity of each band in the gel was quantified by measuring the average and integrated optical density of a standard region encompassing each band (Metamorph software; Universal Imaging). Optical densities were corrected for background and normalized to the total integrated optical density of all bands in the lane. The relative abundance of a given band within a sample was expressed as the percentage of the total signal for all bands within the sample. When comparing the relative difference in the expression pattern between two samples (e.g., samples A and B), the percent difference was calculated as:

$$
\sum\left(\left|A_{1}-B_{1}\right|+\left|A_{2}-B_{2}\right|+\left|A_{3}-B_{3}\right| \cdots+\left|A_{n}-B_{n}\right|\right) / 2
$$

where $\mathrm{A} 1$ is the relative abundance of the first band for sample $\mathrm{A}$ and $\mathrm{B} 1$ is the relative abundance of the first band for sample B. The total number of viral HTA bands is designated by $n$. The absolute values of the differences were used to allow for both increases and decreases in relative abundance. The sum of the total differences was divided by 2 because an increase in the relative abundance of one band must result in the concomitant decrease in another. Therefore, the maximum amount of change between two samples of $100 \%$ would indicate no bands in common between two virus populations. Identical HTA patterns would have a score of $0 \%$.

\section{Specificity of the HTA}

Several negative and positive HTA controls were run with the samples including a sample of the inoculum to give an indication of the HTA pattern for the initial input virus. In addition, the reproducibility of each HTA pattern was verified by running each HTA in duplicate and analyzing sequential samples over time. All major peaks defined in the present analysis were seen in replicate samples, greatly reducing the likelihood that a particular observation was due to a random amplification of a very minor (insignificant) variant. It is also noteworthy that high CSF viral loads induced by the intraventricular inoculations provided high copy numbers of viral RNA for HTA sampling. Lower copy numbers were available for viral DNA but in each case, bands were generally reproduced in duplicate samples and other tissues. We cannot rule out the possibility that low copy numbers in some tissues might have restricted the number of variants that could be resolved. Therefore the absence of bands in tissues was interpreted cautiously. In general, the FIV HTA did not resolve bands as well as HIV-1 HTA. This may be due in part to less sequence variation in the FIV env. Optical density profiles were used to help resolve bands that, in some cases, were not highly distinctive. With these limitations in mind, we were conservative in the identification of major variants (V1 to V7). Each was based on the appearance of very clear peaks in the HTA that were reproduced in multiple samples both within and between animals. 


\section{Statistical analysis}

The statistical significance of the mean percent difference between the paired CSF and plasma at initial or rebounding CSF viral peak, or the mean percent difference in the viral variants between brain regions and PBMCs was determined by a paired $t$ test. The viral diversity in plasma between the i.c.v. cats and i.p. cats was determined by an unpaired $t$ test. Differences were considered significant if the $P$ value was $\leq 0.05$. All statistical calculations were done using Graphpad Prism software.

\section{Acknowledgments}

The study was supported by National Institutes of Health grant MH63646. The authors would like to express their gratitude to Dr. Ron Swanstrom, Dr. Kimberly Ritola, and Dr. Patrick Harrington for their help in the development of the FIV HTA assay.

\section{References}

Ait-Khaled M, McLaughlin JE, Johnson MA, Emery VC. Distinct HIV-1 long terminal repeat quasispecies present in nervous tissues compared to that in lung, blood and lymphoid tissues of an AIDS patient. AIDS. 1995; 9:675-683. [PubMed: 7546410]

Bell JE, Busuttil A, Ironside JW, Rebus S, Donaldson YK, Simmonds P, Peutherer JF. Human immunodeficiency virus and the brain: investigation of virus load and neuropathologic changes in pre-AIDS subjects. J Infect Dis. 1993; 168:818-824. [PubMed: 8376829]

Blumberg BM, Epstein LG, Saito Y, Chen D, Sharer LR, Anand R. Human immunodeficiency virus type 1 nef quasispecies in pathological tissue. J Virol. 1992; 66:5256-5264. [PubMed: 1501274]

Boche D, Hurtrel M, Gray F, Claessens-Maire MA, Ganiere JP, Montagnier, Hurtrel B. Virus load and neuropathology in the FIV model. J Neuro Virol. 1996; 2:377-387.

Bragg D, Childers T, Tompkins M, Tompkins W, Meeker R. Infection of the choroid plexus by feline immunodeficiency virus. J Neuro Virol. 2002a; 8:211-224.

Bragg D, Hudson L, Liang Y, Tompkins M, Fernandes A, Meeker R. Choroid plexus macrophages proliferate and release toxic factors in response to feline immunodeficiency virus. J Neuro Virol. 2002b; 8:225-239.

Burdo TH, Gartner S, Mauger D, Wigdahl B. Region-specific distribution of human immunodeficiency virus type 1 long terminal repeats containing specific configurations of CCAAT/ enhancer-binding protein site II in brains derived from demented and nondemented patients. $\mathrm{J}$ Neuro Virol. 2004; 10 Suppl 1:7-14.

Burkala EJ, He J, West JT, Wood C, Petito CK. Compartmentalization of HIV-1 in the central nervous system: role of the choroid plexus. AIDS. 2005; 19:675-684. [PubMed: 15821393]

Chang J, Jozwiak R, Wang B, Ng T, Ge YC, Bolton W, Dwyer DE, Randle C, Osborn R, Cunningham AL, Saksena NK. Unique HIV type $1 \mathrm{~V} 3$ region sequences derived from six different regions of brain: region-specific evolution within host-determined quasispecies. AIDS Res Hum Retroviruses. 1998; 14:25-30. [PubMed: 9453248]

Chen H, Wood C, Petito CK. Comparisons of HIV-1 viral sequences in brain, choroid plexus and spleen: Potential role of choroid plexus in the pathogenesis of HIV encephalitis. J Neuro Virol. 2000; 6:498-506.

Corboy JR, Garl PJ. HIV-1 LTR DNA sequence variation in brain-derived isolates. J Neuro Virol. 1997; 3:331-341.

Davis LE, Hjelle BL, Miller VE, Palmer DL, Llewellyn AL, Merlin TL, Young SA, Mills RG, Wachsman W, Wiley CA. Early viral brain invasion in iatrogenic human immunodeficiency virus infection. Neurology. 1992; 42:1736-1739. [PubMed: 1513462]

Delwart EL, Shpaer EG, Louwagie J, McCutchan FE, Grez M, Rubsamen-Waigmann H, Mullins JI. Genetic relationships determined by a DNA heteroduplex mobility assay: analysis of HIV-1 env genes. Science. 1993; 262:1257-1261. [PubMed: 8235655] 
Dow SW, Dreitz MJ, Hoover EA. Feline immunodeficiency virus neurotropism: evidence that astrocytes and microglia are the primary target cells. Vet Immunol Immunopathol. 1992; 35:2335. [PubMed: 1337399]

English RV, Johnson CM, Gebhard DH, Tompkins MB. In vivo lymphocyte tropism of feline immunodeficiency virus. J Virol. 1993; 67:5175-5186. [PubMed: 7688819]

English RV, Nelson P, Johnson CM, Nasisse M, Tompkins WA, Tompkins MB. Development of clinical disease in cats experimentally infected with feline immunodeficiency virus. J Infect Dis. 1994; 170:543-552. [PubMed: 8077711]

Epstein LG, Kuiken C, Blumberg BM, Hartman S, Sharer LR, Clement M, Goudsmit J. HIV-1 V3 domain variation in brain and spleen of children with AIDS: tissue-specific evolution within hostdetermined quasispecies. Virology. 1991; 180:583-590. [PubMed: 1989385]

Falangola MF, Hanly A, Galvao-Castro B, Petito CK. HIV infection of human choroid plexus: a possible mechanism of viral entry into the CNS. J Neuropathol Exp Neurol. 1995; 54:497-503. [PubMed: 7602324]

Gonzalez-Scarano F, Martin-Garcia J. The neuropathogenesis of AIDS. Nat Rev Immunol. 2005; 5:69-81. [PubMed: 15630430]

Gorry PR, Taylor J, Holm GH, Mehle A, Morgan T, Cayabyab M, Farzan M, Wang H, Bell JE, Kunstman K, Moore JP, Wolinsky SM, Gabuzda D. Increased CCR5 affinity and reduced CCR5/ CD4 dependence of a neurovirulent primary human immunodeficiency virus type 1 isolate. $\mathrm{J}$ Virol. 2002; 76:6277-6292. [PubMed: 12021361]

Harrington PR, Haas DW, Ritola K, Swanstrom R. Compartmentalized human immunodeficiency virus type 1 present in cerebrospinal fluid is produced by short-lived cells. J Virol. 2005; 79:79597966. [PubMed: 15956542]

Hogan TH, Stauff DL, Krebs FC, Gartner S, Quiterio SJ, Wigdahl B. Structural and functional evolution of human immunodeficiency virus type 1 long terminal repeat CCAAT/enhancer binding protein sites and their use as molecular markers. 2003

Hughes ES, Bell JE, Simmonds P. Investigation of the dynamics of the spread of human immunodeficiency virus to brain and other tissues by evolutionary analysis of sequences from the p17gag and env genes. J Virol. 1997; 71:1272-1280. [PubMed: 8995651]

Johnston JB, Power C. Feline immunodeficiency virus xenoinfection: the role of chemokine receptors and envelope diversity. J Virol. 2002; 76:3626-3636. [PubMed: 11907202]

Liu PH, Hudson LC, Tompkins MB, Vahlenkamp TW, Colby B, Rundle C, Meeker RB. Cerebrospinal fluid is an efficient route for establishing brain infection and seeding peripheral systems with feline immunodeficiency virus. J Neuro Virol. 2006; 12:294-306.

Morris A, Marsden M, Halcrow K, Hughes ES, Brettle RP, Bell JE, Simmonds P. Mosaic structure of the human immunodeficiency virus type 1 genome infecting lymphoid cells and the brain: evidence for frequent in vivo recombination events in the evolution of regional populations. $\mathrm{J}$ Virol. 1999; 73:8720-8731. [PubMed: 10482626]

Nelson JA, Fiscus SA, Swanstom R. Evolutionary variants of the human immunodeficiency virus type $1 \mathrm{~V} 3$ region characterized by using a heteroduplex tracking assay. J Virol. 1997; 71:8750-8758. [PubMed: 9343234]

Petito CK, Chen H, Mastri AR, Torres-Munoz J, Roberts B, Wood C. HIV infection of choroid plexus in AIDS and asymptomatic HIV-infected patients suggests that the choroid plexus may be a reservoir of productive infection. J Neuro Virol. 1999; 5:670-677.

Phillips T, Prospero-Garcia O, Puaoi D, Lerner D, Fox H, Olmsted R, Bloom F, Heriksen S, Elder J. Neurological abnormalities associated with feline immunodeficiency virus infection. J Gen Virol. 1994; 75:979-987. [PubMed: 8176384]

Power C, Buist R, Johnston JB, Del Bigio MR, Ni W, Dawood MR, Peeling J. Neurovirulence in feline immunodeficiency virus-infected neonatal cats is viral strain specific and dependent on systemic immune suppression. J Virol. 1998; 72:9109-9115. [PubMed: 9765456]

Power C, McArthur JC, Johnson RT, Griffin DE, Glass JD, Perryman S, Chesebro B. Demented and non-demented patients with AIDS differ in brain-derived human immunodeficiency virus type 1 envelope sequences. J Virol. 1994; 68:4643-4649. [PubMed: 8207838] 
Power C, Zhang K, van Marle G. Comparative neurovirulence in lentiviral infections: The roles of viral molecular diversity and select proteases. J Neuro Virol. 2004; 10 Suppl 1:113-117.

Ritola K, Robertson K, Fiscus SA, Hall C, Swanstrom R. Increased human immunodeficiency virus type 1 (HIV-1) env compartmentalization in the presence of HIV-1-associated dementia. J Virol. 2005; 79:10830-10834. [PubMed: 16051875]

Ryan G, Klein D, Knapp E, Hosie MJ, Grimes T, Mabruk MJ, Jarrett O, Callanan JJ. Dynamics of viral and proviral loads of feline immunodeficiency virus within the feline central nervous system during the acute phase following intravenous infection. J Virol. 2003; 77:7477-7485. [PubMed: 12805447]

Scarlatti G, Tresoldi E, Bjorndal A, Fredriksson R, Colognesi C, Deng HK, Malnati MS, Plebani A, Siccardi AG, Littman DR, Fenyo EM, Lusso P. In vivo evolution of HIV-1 co-receptor usage and sensitivity to chemokine-mediated suppression. Nat Med. 1997; 3:1259-1265. [PubMed: 9359702]

Schrager LK, D'Souza MP. Cellular and anatomical reservoirs of HIV-1 in patients receiving potent antiretroviral combination therapy. JAMA. 1998; 280:67-71. [PubMed: 9660366]

Shapshak P, Segal DM, Crandall KA, Fujimura RK, Zhang BT, Xin KQ, Okuda K, Petito CK, Eisdorfer C, Goodkin K. Independent evolution of HIV type 1 in different brain regions. AIDS Res Hum Retroviruses. 1999; 15:811-820. [PubMed: 10381169]

Smit TK, Brew BJ, Tourtellotte W, Morgello S, Gelman BB, Saksena NK. Independent evolution of human immunodeficiency virus (HIV) drug resistance mutations in diverse areas of the brain in HIV-infected patients, with and without dementia, on antiretroviral treatment. J Virol. 2004; 78:10133-10148. [PubMed: 15331746]

Strain MC, Letendre S, Pillai SK, Russell T, Ignacio CC, Gunthard HF, Good B, Smith DM, Wolinsky SM, Furtado M, Marquie-Beck J, Durelle J, Grant I, Richman DD, Marcotte T, McCutchan JA, Ellis RJ, Wong JK. Genetic composition of human immunodeficiency virus type 1 in cerebrospinal fluid and blood without treatment and during failing antiretroviral therapy. J Virol. 2005; 79:1772-1788. [PubMed: 15650202]

Torres-Munoz J, Stockton P, Tacoronte N, Roberts B, Maronpot RR, Petito CK. Detection of HIV-1 gene sequences in hippocampal neurons isolated from postmortem AIDS brains by laser capture microdissection. J Neuropathol Exp Neurol. 2001; 60:885-892. [PubMed: 11556545]

van Marle G, Henry S, Todoruk T, Sullivan A, Silva C, Rourke SB, Holden J, McArthur JC, Gill MJ, Power C. Human immunodeficiency virus type 1 Nef protein mediates neural cell death: a neurotoxic role for IP-10. Virology. 2004; 329:302-318. [PubMed: 15518810]

van Marle G, Power C. Human immunodeficiency virus type 1 genetic diversity in the nervous system: evolutionary epiphenomenon or disease determinant? J Neuro Virol. 2005; 11:107-128.

Willett BJ, Flynn JN, Hosie MJ. FIV infection of the domestic cat: an animal model for AIDS. Immunol Today. 1997; 18:182-189. [PubMed: 9136455]

Wong JK, Ignacio CC, Torriani F, Havlir D, Fitch NJ, Richman DD. In vivo compartmentalization of human immunodeficiency virus: evidence from the examination of pol sequences from autopsy tissues. J Virol. 1997; 71:2059-2071. [PubMed: 9032338]

Yang J-S, English RV, Ritchey JW, Davidson MG, Wasmoen T, Levy JK, Gebhard DH, Tompkins MB, Tompkins WAF. Molecularly cloned feline immunodeficiency virus NCSU1 JSY3 induces immunodeficiency in specific-pathogen-free cats. J Virol. 1996; 70:3011-3017. [PubMed: 8627777]

Zink MC, Amedee AM, Mankowski JL, Craig L, Didier P, Carter DL, Munoz A, Murphey-Corb M, Clements JE. Pathogenesis of SIV encephalitis. Selection and replication of neurovirulent SIV. Am J Pathol. 1997; 151:793-803. [PubMed: 9284828] 
A.

ss probe

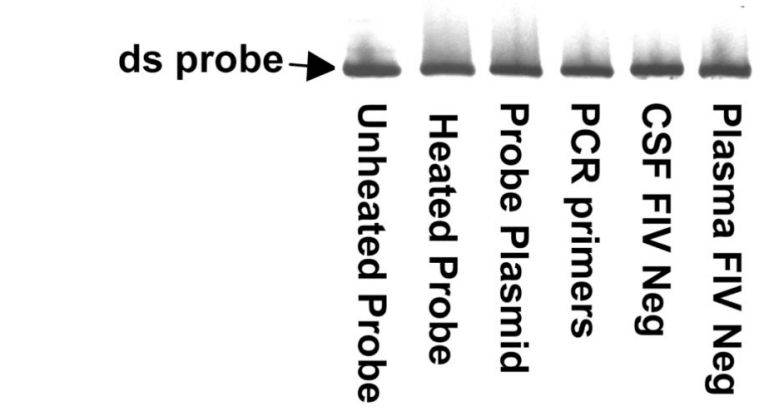

B.

Cat \#6

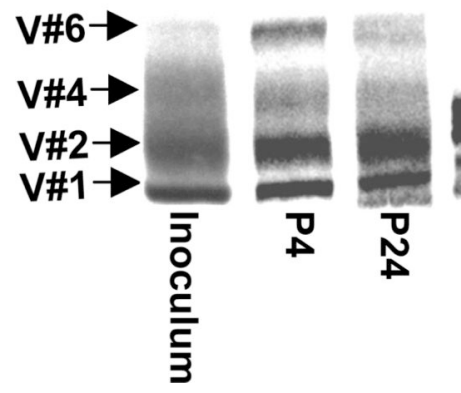

C.

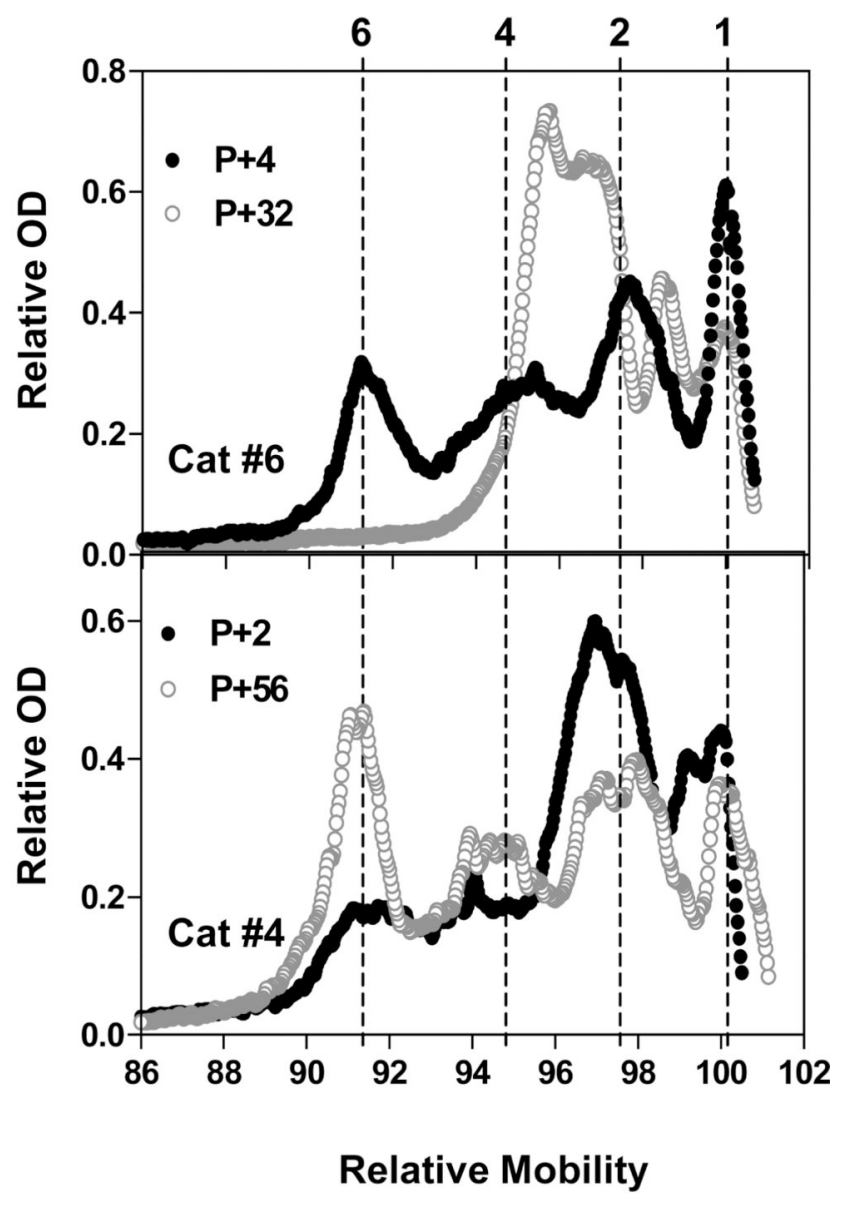

Figure 1.

V3-V4 HTA patterns of the plasma (P) FIV over time in two typical cats. A, The negative controls of FIV NCSU 1 env V3-V4-specific HTA. $\mathrm{S}^{35}$-labeled probes were run with (heated) or without the denaturing step (unheated), or probes were run with the internal primers for nested PCR (PCR primers), or with the PCR product of the probe plasmid and uninfected (FIV Neg) control samples. The single-stranded probe (ss probe) and the fastest migration homoduplex (ds probe) are indicated by arrows. B, The plasma HTA patterns of two typical cats. Plasma sampled at the time of the initial CSF peak, the second CSF peak and the final time point was selected to analyze viral env evolution over time. The inoculum was also run to show the initial virus mix. The lower portion of gel containing all the heteroduplexes is shown. The week post inoculation is indicated at the bottom of each lane (e.g., P4 = plasma at 4 weeks). $\mathbf{C}$, The optical density profile of the V3-V4 HTA pattern at the initial plasma viremia and the last time point in cat 6 and cat 4 . The optical density and mobility was measured by Metamorph software after scanning the x-ray films. The relative optical density and mobility was calculated as described in Materials and Methods. 
According to their relative mobility, the major variants were designated V1 to V7. The number above the dashed line identifies each variant. 


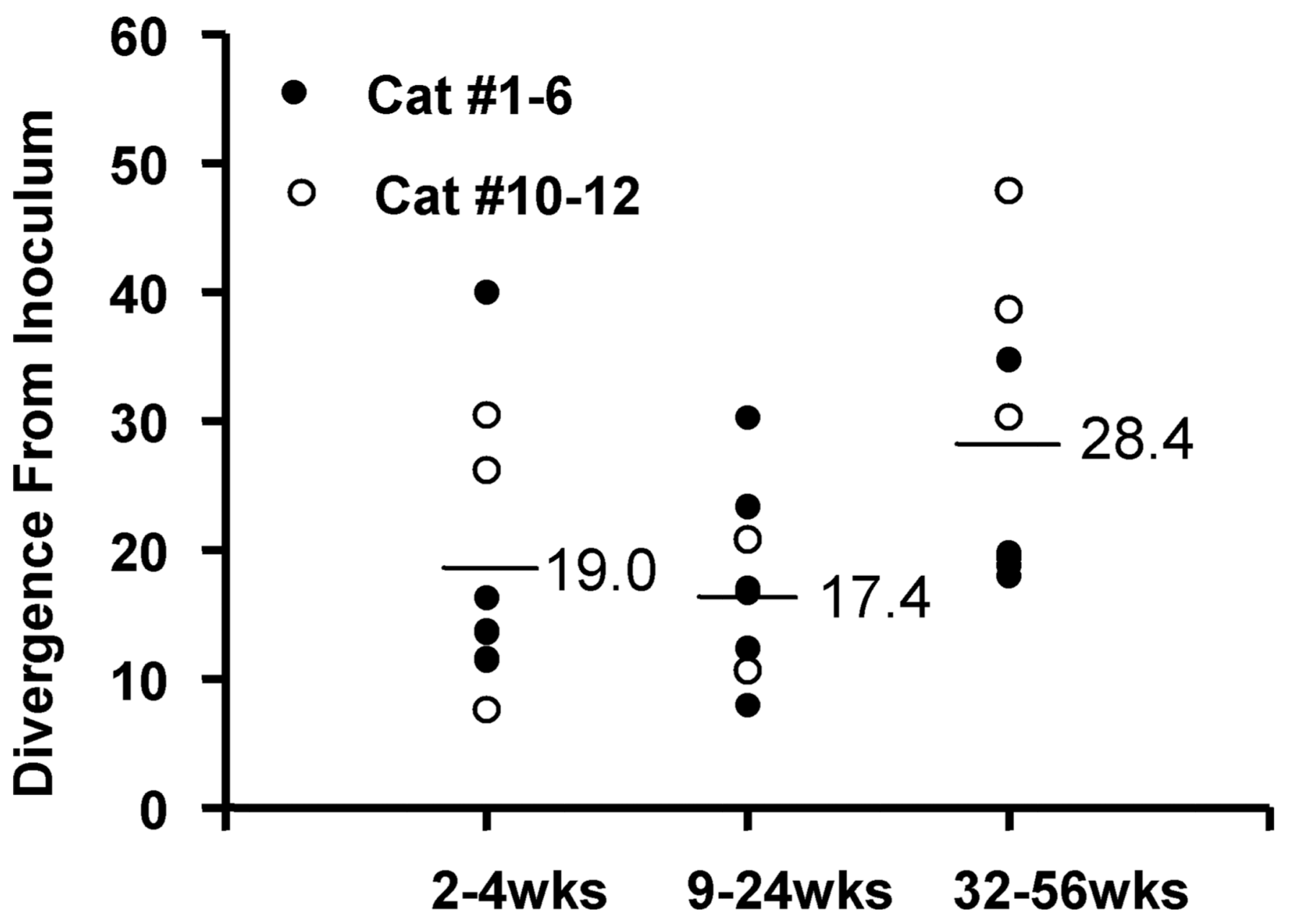

Figure 2.

Viral evolution in plasma over time for each cat following i.c.v. or i.p. inoculation. The FIV env genotypes in plasma were analyzed by HTA. The divergence from the inoculum at each time point was calculated and plotted at intervals representing the initial viremia ( 2 to 4 weeks), the time during which the second CSF peak emerged ( 9 to 24 weeks) and the final time point at euthanasia. Each point reflects the divergence seen for an individual cat. The black circles represent the i.c.v. cats (cats 1 to 6 ) and the open circles represent the i.p. cats (cats 10 to 12). The horizontal bar and number illustrate the mean value. 
A. Cat \#6

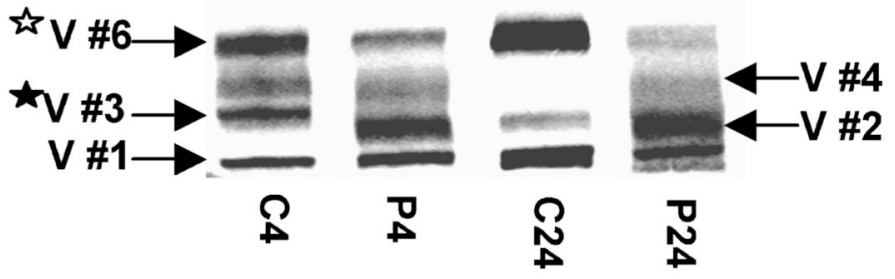

B.

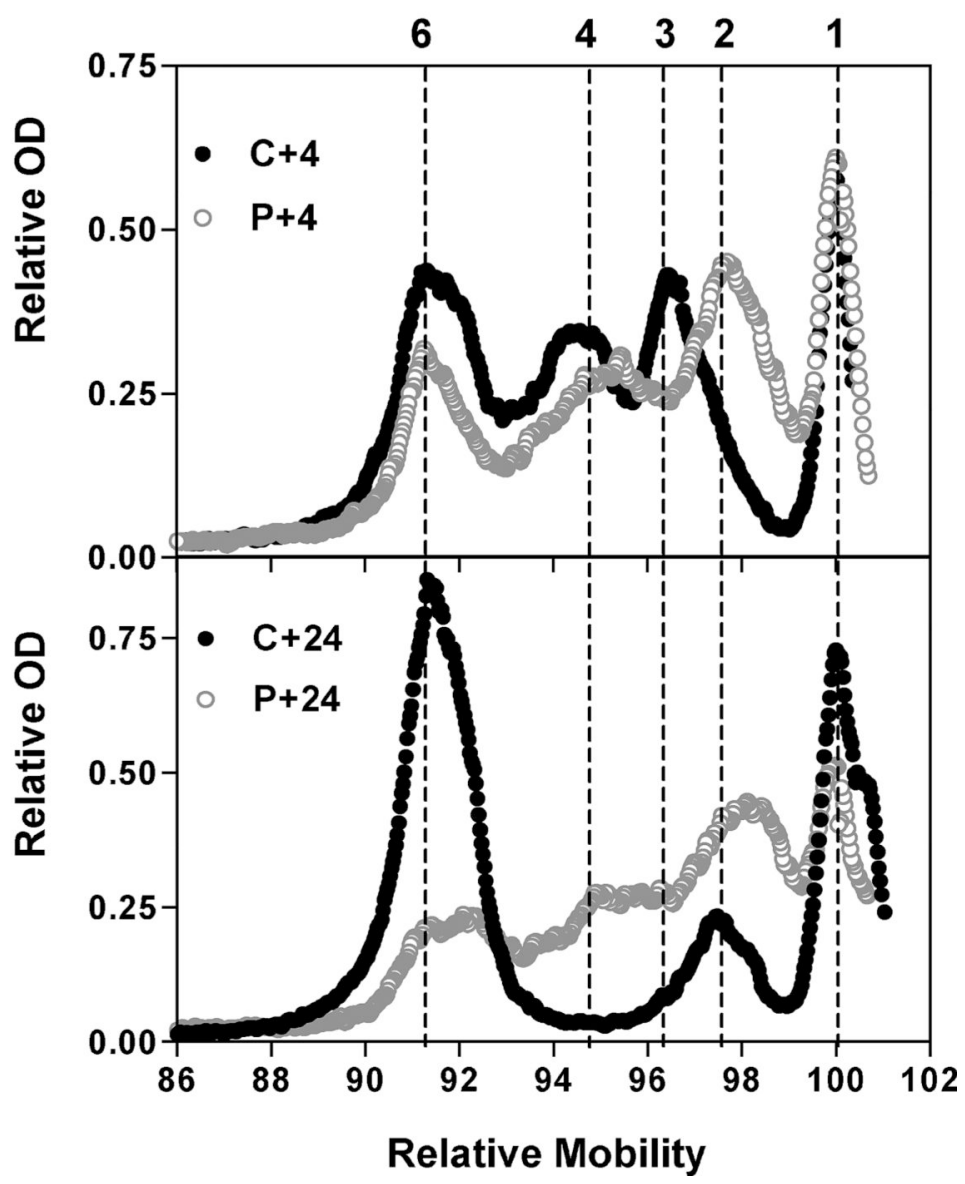

Figure 3.

Comparison of V3-V4 env variants in paired CSF (C) and plasma (P) samples at the initial and second CSF viral peak in cat 6 . A, The HTA patterns from CSF (C) and plasma (P) sampled at 4 and 24 weeks post inoculation. The bottom portion of the gel containing all the heteroduplexes is shown. A variant unique to the CSF at this time point (V3 marked with the solid star) and a variant enriched in the CSF (V6 marked with the open star) are seen in these samples. B, The optical density profiles illustrating the quantification of the HTA patterns in the gel. The number above the dashed line identifies each variant. 
A.
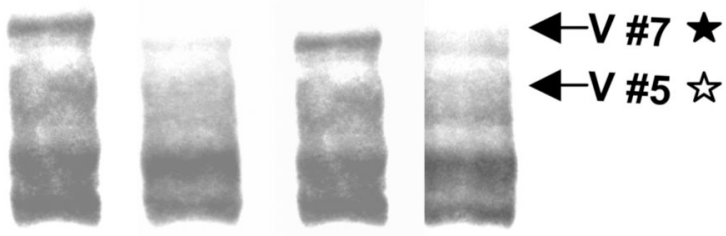

న

D

$8 \quad 7$

B.

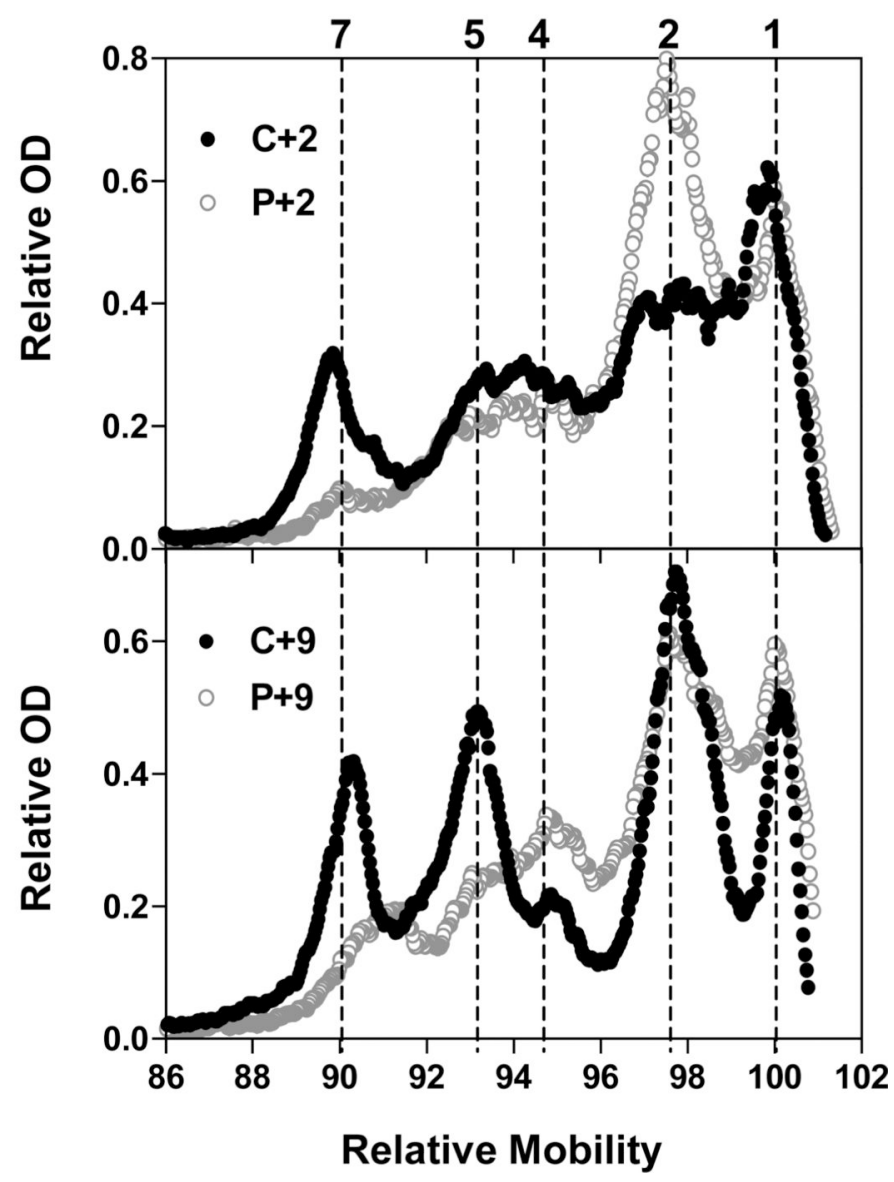

Figure 4.

Comparison of V3-V4 env variants in the paired CSF (C) and plasma (P) samples for the initial or second CSF viral peak in cat 5. A, The HTA patterns of the CSF (C) and plasma (P) at 2 and 9 weeks post inoculation are illustrated. A variant is seen in the CSF that is not apparent in the plasma (V7 marked with the solid star) as well as a variant that is enriched in the CSF (V5 marked with the open star). B, The optical density profiles illustrating the quantification of the HTA patterns in the gel. The number above the dashed line identifies each variant. 

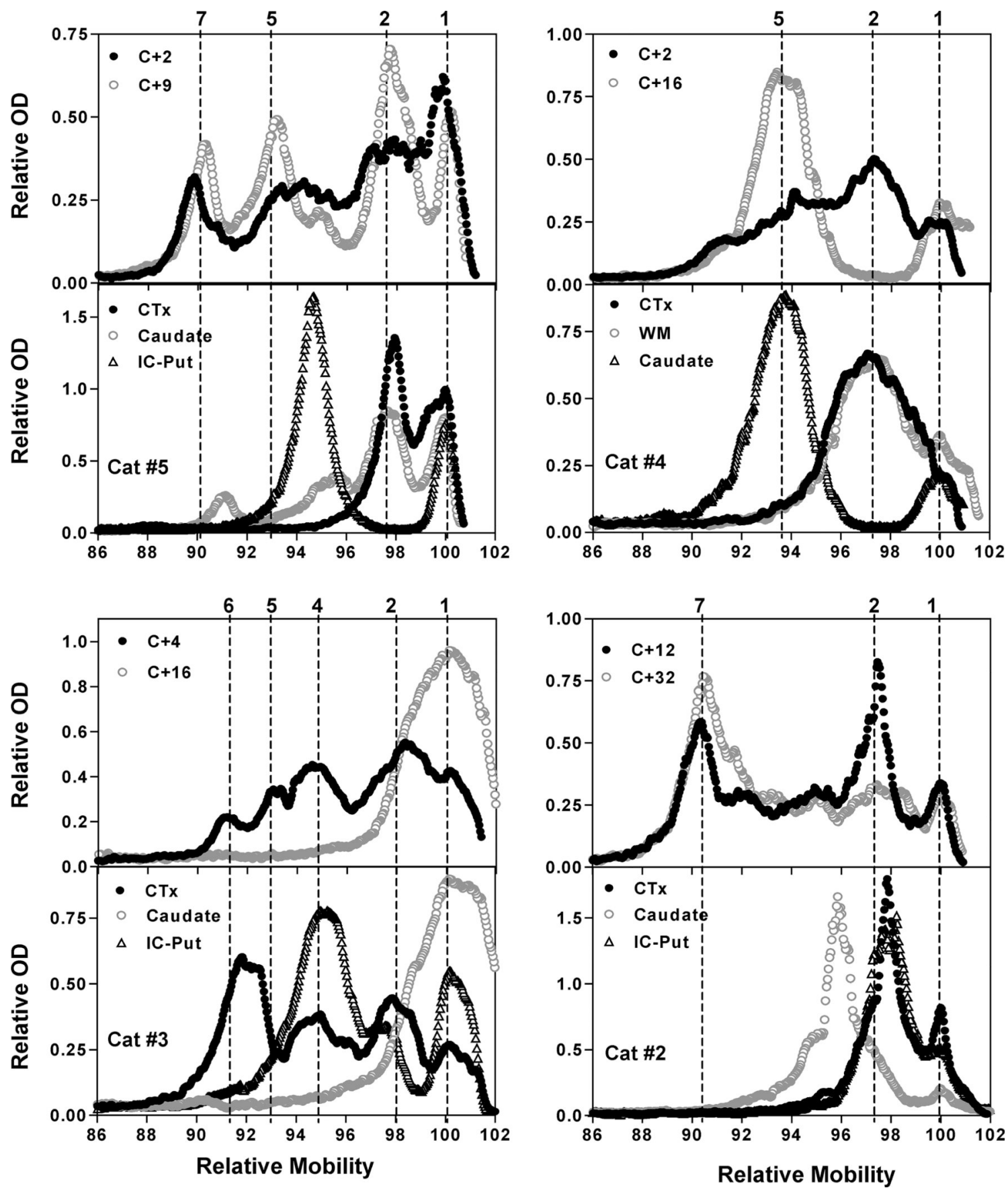

Figure 5.

Comparison of V3-V4 env variants in the CSF (top panel) and various brain regions (bottom panel). The env variants in the CSF FIV RNA for the first and second CSF viral peaks and the FIV DNA from the brain regions at euthanasia were characterized by V3-V4 HTA. The optical density profiles from four cats are shown to illustrate the variation in HTA patterns. The dashed line marks the position of major variants in the CSF. CTX, frontal cortex gray matter; WM, underlying cortical white matter; IC-Put, internal capsule/putamen. 

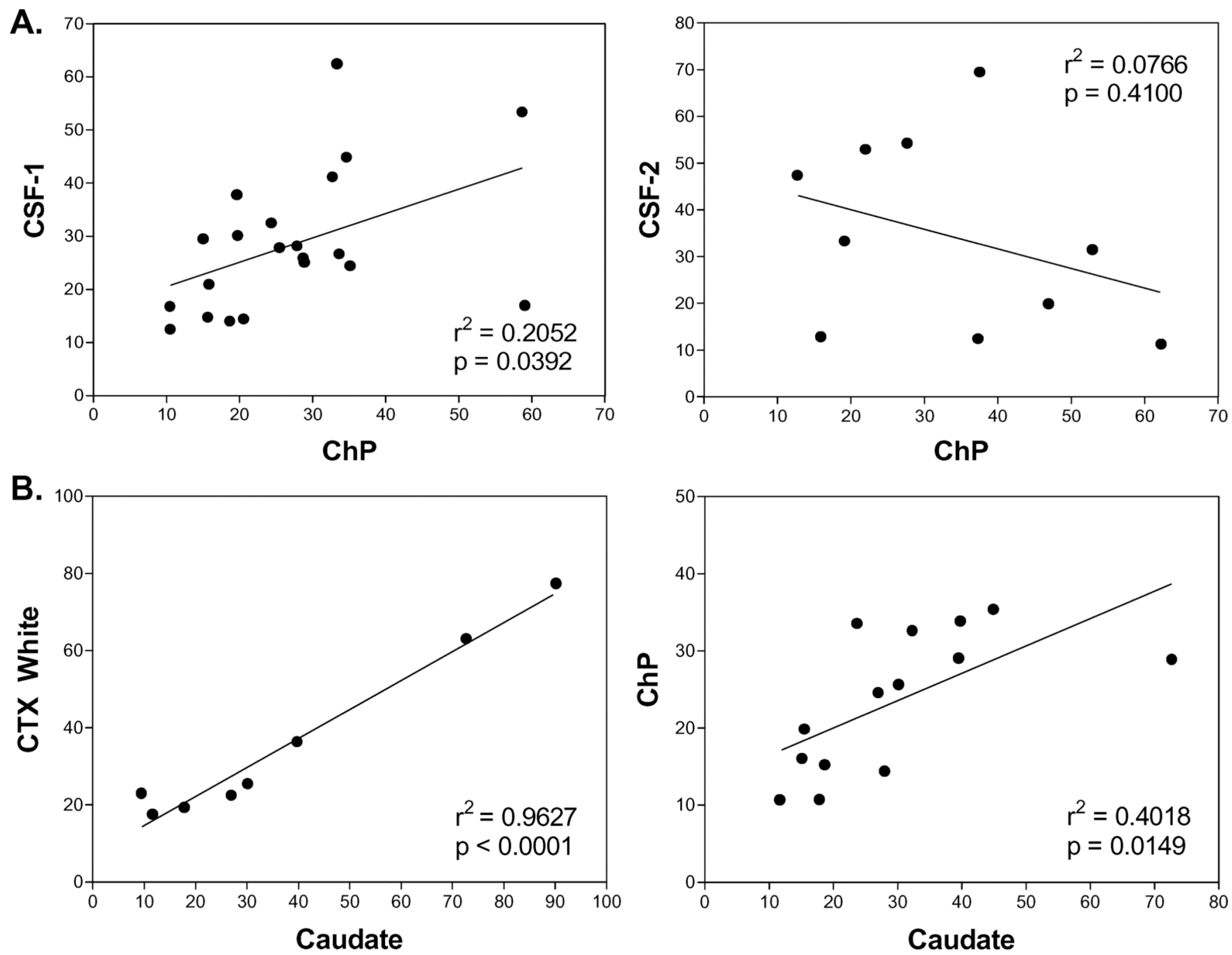

Figure 6.

Correlation of the abundance of shared variants between periventricular regions. A, Correlation of the relative abundance of shared variants between the choroid plexus (ChP) and CSF. Variants expressed in both the choroid plexus and the CSF were compared based on their relative abundance. The abundance of these shared variants in the ChP was significantly correlated with the variants in the initial CSF peak but not the second peak. B, Correlation of the relative abundance of the shared variants between caudate and the subcortical white matter (CTX White) or the ChP. A significant correlation in the abundance of FIV DNA variants was seen between the periventricular tissue regions. 


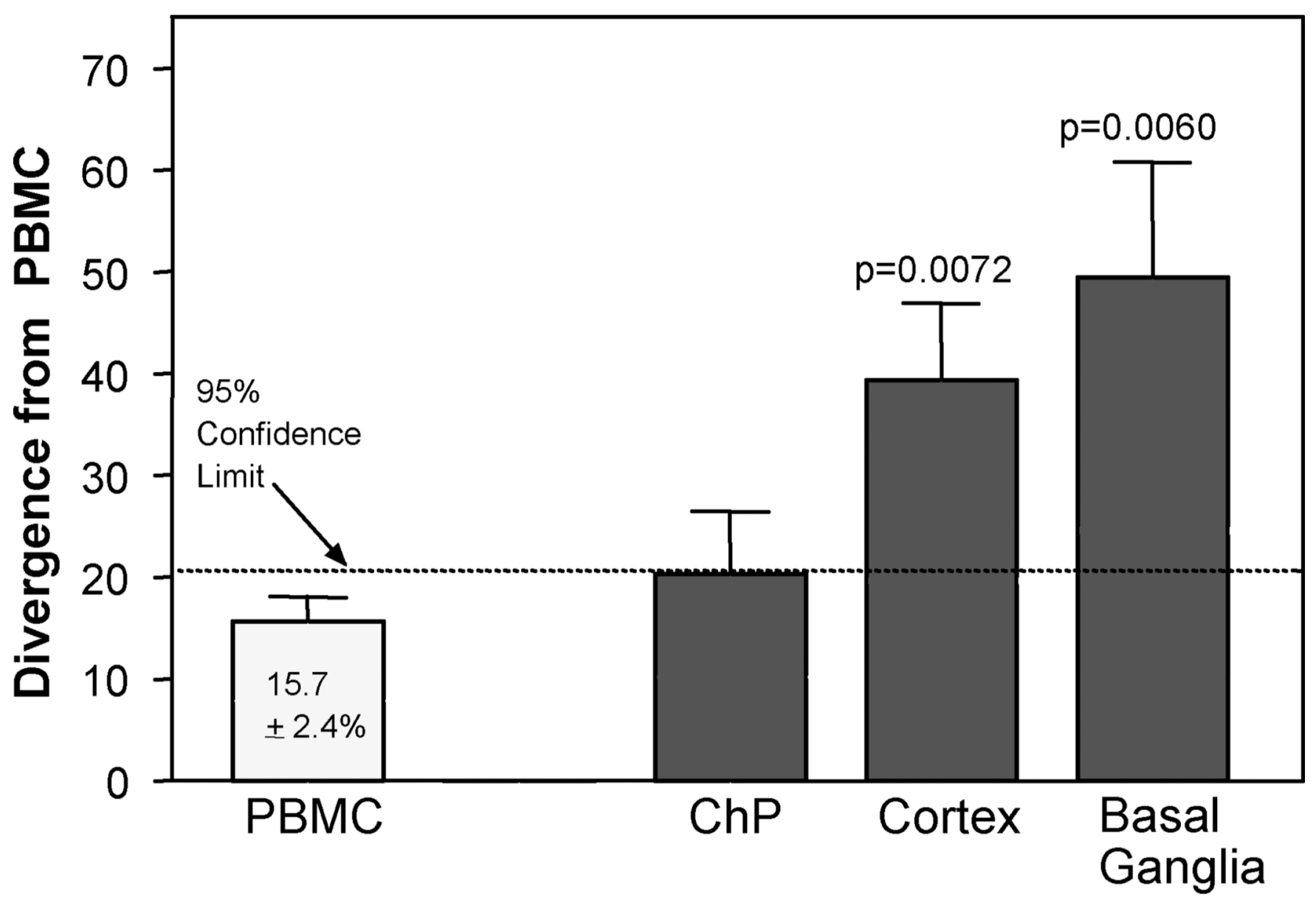

Figure 7.

The average divergence of proviral DNA in the choroid plexus (ChP), cortex, and basal ganglia from matched PBMCs. Divergence of the HTA patterns of PBMCs was first calculated relative to the inoculum to provide an indication of the variability in FIV proviral env sequences across all cats. These sequences were found to be relatively stable with an average divergence of $15.7 \% \pm 2.4 \%$. The $95 \%$ confidence limit was calculated and used as a reference for normal variation in FIV env DNA sequences (dashed line). The ChP, the cortex (the frontal cortex gray matter and subcortical white matter CTX-white combined) and the basal ganglia (caudate nucleus and internal capsule/putamen combined) in each cat were compared with the time matched PBMCs. The mean diversity from the matched PBMC HTA profile $( \pm$ SEM) is shown. $P$ values reflect the comparison $(t$ test) of each region to matched $\mathrm{PBMCs}$. 

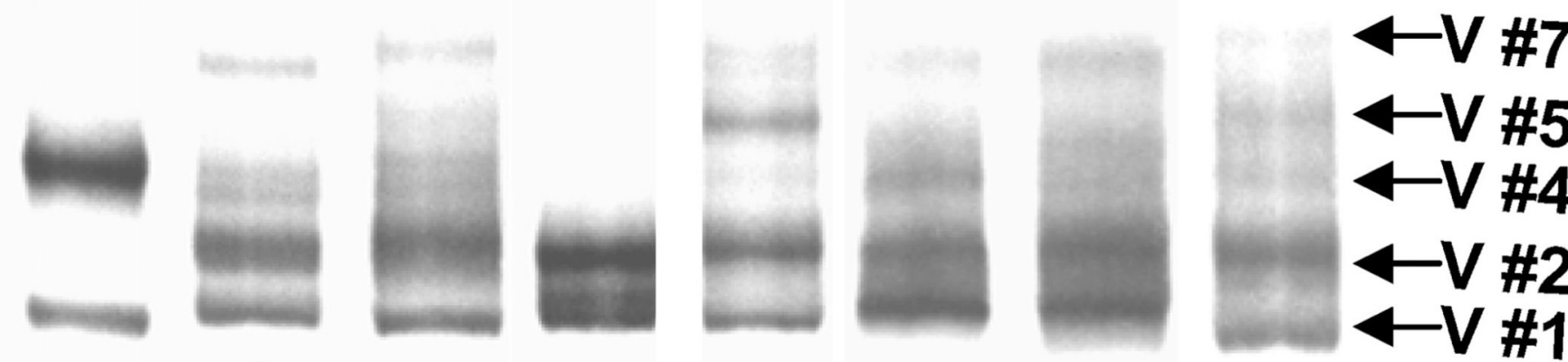

0
1
1

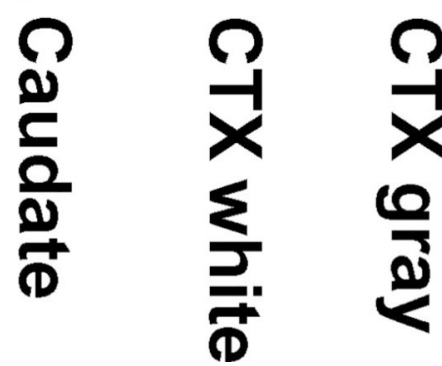

$\frac{0}{0}$

5

$\frac{\mathbf{0}}{\mathbf{0}}$

$\frac{0}{0}$

Figure 8.

Analysis of V3-V4 variants in the CNS, blood and lymph node at euthanasia by V3-V4specific HTA in cat 5. Considerable variation in FIV V3-V4 env HTA is seen between different brain regions while systemic tissues (LN, PBMCs, and plasma) are more homogeneous. This type of variation was typical across all cats although each showed a unique pattern. CTX-gray, frontal cortex gray matter; CTX-white, subcortical white matter; IC-Put, internal capsule/putamen; ChP, choroid plexus; LN, superficial cervical lymph node. Arrows show the position of specific variants. 
